\title{
Three Points in Time: How Values and Culture Affected My Life, Madness and the People Around Me
}

\author{
David Crepaz-Keay
}

\subsection{Introduction}

The experience of hearing and seeing things that others do not, when it brings the observed behaviour of the person experiencing it into conflict with what is expected of them, is commonly regarded as a psychiatric problem. This has, in the western world, historically been regarded as a clinical problem that requires a clinical solution.

In this chapter, I explore three stories taken from my teens and twenties as I was growing up hearing and seeing things in middle class middle England. The impact of these experiences on my life, both in the moment and on its future direction, was affected as much by the culture it took place in as by any clinical conditions or responses.

\subsection{Episode One: Schizophrenia Is Just Like Diabetes...(Circa 1979-1982)}

I started hearing and seeing things in my early teens (in the late 1970s). They were frightening things and my responses ranged from flinching to running away or hiding, depending on the severity. This was initially an infrequent occurrence and though I'm sure it caused my parents concern; it only became an issue when it happened in the presence of people outside the immediate family. As the frequency of "escapes" increased I was taken to see our family doctor, but I did not find him someone I could talk to. After several years and several diagnoses, I found myself with a diagnosis of schizophrenia and on antipsychotic medication.

\footnotetext{
D. Crepaz-Keay $(\bowtie)$

Applied Learning, Mental Health Foundation, London, UK 
My father had type one diabetes and took daily insulin. On the rare occasions that he experienced a "hypo" his behaviour became extremely unusual and the family had a well-established plan to respond. Our doctor described schizophrenia as "just like diabetes, as long as David takes his medication, he will mostly be fine; it's not $100 \%$ effective but it's very dangerous to not treat this illness."

Like many people with the same diagnosis I found that the medication had no effect on what I heard or saw, but it did make running away a lot more difficult. With my escapes less frequent (and when they did happen, a lot slower), my parents were, if not delighted, at least satisfied. I was both increasingly frustrated and less willing/ able to articulate my concerns and this unstable hiatus held for some time.

Nothing really prepared me for the experience of hearing and seeing things; it was the most frightening experience of my life. Although I was reluctant to talk about the experiences themselves, my reactions to the things I could see and hear and my subsequent "fight/flight" (predominantly the latter) responses meant that medical involvement was inevitable. I had always got on well with our family doctor and so when he explained that my experience was an illness like many others, I initially found this reassuring; particularly, the only alternative I could think of was that I was going mad.

Unfortunately, the medication I was prescribed failed to prevent me from hearing and seeing things. It did, however, affect my thinking, feeling, speed and balance. When I explained this, I was given different doses and variants, but they all had the same lack of impact on what I was seeing and hearing and made little difference to the (substantial) negative effects of the drugs.

The impact of these effects was that I responded less rapidly to what I was seeing and hearing. To me, this made the experience more frightening, but to those around me, I seemed calmer and my behaviour less disturbing and unusual. I continued to describe the effects as unhelpful and disruptive, while my parents told the doctor that I appeared to be much better. In short, the perceived impact of my experiences and the efficacy (or otherwise) of treatment was affected by the values of the perceivers.

A summary of the key values is presented in Box 22.1.

\section{Box 22.1 Values in Episode One}

\section{The Family Doctor}

- His primary relationship was with my family, this had been a long-standing relationship and the larger part of this had centred around managing my father's diabetes.

- His approach to me was based wholly on a simple illness-treatment control-control of symptoms model and I'm sure that he would have seen this as entirely objective in terms of culture and values.

- If forced to consider values and culture, success would be based on achieving a normal healthy nuclear family, by treating illness with the prescribed medicine. 


\section{My Family}

- My family's values and culture were strongly influenced by a desire for their children to achieve more than they had (they had both been the first in their respective families to have white collar jobs, whereas their parents were blue collar and such things were important to them). At that time, this meant $\mathrm{O}$ levels, $\mathrm{A}$ levels and a university degree.

- They were also drawn to a medical explanation of my behaviour; it matched their experience of diabetes and removed any sense of responsibility for my condition.

- They would not have challenged a medical opinion and would take the view of a doctor as gospel.

Me

- I very much wanted to be "normal", just like my friends. I definitely did not want to be "mad" or mental".

- I respected medical opinion but was disappointed that I was treated as a family son not as an individual.

- I valued my schoolwork and friends and felt my treatment was impairing both without affecting my hearing and seeing things.

\subsubsection{Cultural Influences}

In addition to the impact of values, the cultural context was also important. The middle-class middle England culture of social improvement and deference to medical professionals was a strong influence on this stage of my life and development. Clearly, a desire to achieve the best for me was the strongest cultural influence; the goal of me being the first in the family to go to university was shared by all of us; but sometimes, I think social embarrassment was a strong motivator.

\subsection{Episode Two: The Great Escape... (Circa 1985-1987)}

I found myself detained in a secure ward in the psychiatric department of a large hospital just north of Slough. I was told I had been "sectioned"; I had no idea what this meant and just wanted to know when I could leave.

The environment was entirely alien to me and it took a long while to get to grips with it. For the first week or so I just wanted to leave but once I started talking to the other patients everything became a little easier. The medication was still not affecting what I saw or heard but it become clear that this was quite common amongst us.

Staff contact was minimal, and most was with student nurses, porters or cleaners. Qualified nurses stayed in the office or were off ward entirely. The psychiatrist was pleasant but only visited weekly. 
I eventually settled into a comfortable inertia which seemed to be regarded as a positive outcome by pretty much everyone. We started to receive regular visits from a remarkable woman who ran the local Mind; she told me to stop wasting my talents, get out and do something more useful with my life.

The key to escape was to be seen as "normal" and the person to convince was my psychiatrist. Fortunately, an enthusiasm for cricket and a sound knowledge of economic policy and practice seemed to be the key skills required for this task.

Life on the ward as a detained patient was unlike anything I had ever experienced. Our movements severely constrained (constraints that were equally applied to patients whether they were subject to detention under the mental health act or not). Restrictions were not limited to our movements; information about treatments (which at that time meant either drugs or electroconvulsive therapy (ECT)) was not freely available. Plain language leaflets about medication, which were published by Mind, were distributed by volunteer visitors but confiscated by staff. Negative comments about treatment regimens were regarded as symptoms of illness or lack of insight. Anyone caught not taking oral medication would be switched to injections. If we refused to comply with injected medication, restraint was used (this was a routine occurrence); if patients repeated this behaviour, we would be subject to seclusion.

Wards were highly hierarchical, with the consultant psychiatrist at the top and clear demarcations at each subsequent clinical level. Although the psychiatrist was clearly the person who made the clinical decisions, including the most important one regarding discharge, they only saw us every other week at best. Nurses were more present, but even they spent most of their time in nursing offices with the doors firmly shut and they took a dim view of any interruptions. Conversations with nursing staff were entirely at times of their choosing and only about symptoms and treatments. Student nurses and domestic staff were around much more of the time and most of our social interactions were either with these staff or with each other as patients.

My main recollection of time on the ward was of boredom. Any contact with the outside world was exciting and the regular visitor from the local Mind association was the one person who remained ambitious for me. My primary goal was to get out of hospital for good. The titular great escape did not involve motorcycles, vaulting horses or any great physical feats; rather, it meant appearing to be "normal" and that this meant not questioning clinical regimes and not causing any kind of disruption (incidentally, the skill of pretending to be normal is very useful in day-to-day life) (Box 22.2).

\section{Box 22.2 Values in Episode Two}

Me

- I wanted to be out of this environment, driven by values of independence, distrust of the clinical approach, which I knew was not working, but an understanding of the importance of "playing the game". 


\section{Consultant Psychiatrist}

- Had a clear idea of what normal was and this seemed to entirely match the values I was brought up with: the manners, knowledge and life experiences (by now, I was at university and had started working for the civil service during my holidays).

- Expected adherence to treatment and a return to conventional behaviour.

- Was clearly used to being at the summit of ward hierarchy and this was universally accepted.

\section{Student Nurses and Non-clinical Staff}

- The most compassionate and humane of all I came into contact with during my stay.

- Almost universally seemed to be driven by a desire to make our time there as pleasant as possible.

- Present more often than anyone else and much more likely to engage in conversation that was not about medication or symptoms.

\section{Hospital Visitor}

- Driven by a desire to see people reach their potential.

- Directive and assertive in style, she was not afraid to tell people what she thought they should do.

- Her style put off as many people as it appealed to- - she had the ambition for me that had been sapped by defensive psychiatric practices and excessive medication.

\subsubsection{Cultural Influences}

Although it is common to talk of "ward culture," it would probably be more accurate to consider "ward cultures."

There was the day-to-day culture of normal life on the ward. This was generally comfortable if dull. Hierarchies were apparent throughout and were not restricted to the clinical staff side. Even as patients we group ourselves in a number of ways, including diagnosis, medication and duration of detention.

The nursing culture was designed to deliver a quiet and controlled ward and levels of medication, seclusion and restraint were all used to maintain this. Most interaction with nursing staff centred around medication or food. There was little social interaction between staff and patients (apart from with student nurses). Discussion about medication and treatment was actively discouraged and the notion of informed consent was quite absent. Every now and then, we (patients) would get hold of a BNF or perhaps a Mind leaflet on treatment, but these would be confiscated if discovered. 
The psychiatric culture was one of the quiet authority and it was clear that the ward (and indeed the department) was his domain. As the psychiatrist was the ultimate judge of "normal," it was extremely helpful for me that we came from similar social backgrounds and in many ways his "normal" was my aspirational "normal".

Pam, the hospital visitor, was entirely counter-cultural in this respect (and most other respects). She believed that people should be in control of their own lives. It is not clear how she achieved this in the then-prevailing culture.

\subsection{Episode Three: Every Cloud... (Circa 1992)}

At the end of a prolonged experience of hearing and seeing a sinister cloud, I found myself running through the Chilterns in only my pyjamas, dressing gown and slippers. It was a stormy night and I was soaked through and over five miles from home. I found a telephone box and called my then girlfriend asking for help.

We had been going out for a couple of months or so and she was aware of my psychiatric history but had no first-hand experience of me hearing and seeing things with this degree of impact. I had met her mother a few times and we got on well.

They both came to collect me, took me home and looked after me until we all agreed it was fine for them to leave me. About a year later we were married and last year we celebrated our 25th wedding anniversary...

Until this point, I had taken an individual approach to what might these days be referred to as my recovery. The goal being to get by on my own and to be able to cope with all that is thrown at me. This was a reasonable response to the illness/deficit model that I had initially been confronted by and the emphasis placed on individual "wellness" (the normality of episode two). The important development in my own values was the understanding that the meaningful and fulfilling life I sought was more about how I related to others than how independent I could be.

I was fortunate to find not just one person who shared and explicitly exhibited these values, but two. Their response to me at my most "mad", and my willingness to seek support from them at that point, was the most significant event in my development from dependence, through independence to interdependence.

The behaviours of all players in this episode took a degree of confidence in each other that defied rational analysis, but which came to define my values from that point on (Box 22.3).

\section{Box 22.3 Values in Episode Three}

Me

- My final steps towards interdependence. The first time I really trusted a third party as a part of how I might survive and thrive in the context of hearing and seeing things. 


\section{My Girlfriend}

- Driven by a desire to understand what the right thing to do was and how it might be done.

- Instinctively humane and compassionate.

- Sceptical of a clinical approach to something that defied any explanation.

\section{Her Mother}

- Integrity and a desire to do the best for her daughter and, by extension, someone who was important to her.

- Entirely non-judgmental of my "condition".

- Compassionate and supportive.

\subsubsection{Cultural Influences}

The culture of support and compassion without clinical judgement shone through. It echoes and amplifies the culture and values exhibited by student nurses, cleaners and porters from episode two. These are values which I aspire to and which have influenced the way I work.

\subsection{Conclusions}

In this chapter, I have explored the impact of cultural values on mental health through a series of episodes from my own experience of "psychosis" over a number of years. Key to these experiences was the extent of the match between my own cultural background and various cultures in which I found myself. Thus, in episode, "schizophrenia is just like diabetes," the culture of my family and the immediate community around me placed my non-conformist experiences firmly in the clinical space as a simple chemical imbalance that could be managed with carefully titrated medication; in episode two, "the great escape," variations in what the prevailing culture considered normal directly affected decisions about how people would be detained and treated; in episode three, "every cloud," the simplest of human values helps mitigate a complicated and distressing problem. None of this is to argue that mental health services could be replaced by simple kindness - just that the values and cultures of different participants and organisations (and in particular the differences between them) have a clear impact on both processes and outcomes in mental health.

A number of important themes emerge from my story: the diversity of individual experiences of madness; the importance of context (including cultural context) on the outcomes (favourable or unfavourable) of these experiences and, perhaps most importantly, the importance of narrative within the "oral tradition of the survivor movement," in allowing one's own story to be told rather than someone else "putting it up on a power point." 
Acknowledgements I would like to acknowledge the importance of all those who have enabled me to live a mad life well: the pioneers of the survivor movement who fought for so many then counter-cultural principles which we now take for granted, allies who gave us the space and support to battle effectively, my close friends who value me, and above all Margaret and Lavinia who have given me a mad life worth living and values to aspire to.

\subsection{Guide to Further Sources}

Although it is somewhat daunting to explore the full range of cultures available, searching for the following terms will broaden most people's cultural horizons: "hearing voices", "white privilege". For those too young to understand ward culture in the 1970s and 1980s the following always remind me where we've come from: "on being sane in insane places" [1] and "one flew over the cuckoo's nest" [2] (please note other cultures are available).

\section{References}

1. Rosenhan D. On being sane in insane places. Science. 1973;179:250-25.

2. Kesey K. Penguin Classics edition (2005) One flew over the cuckoo's nest. The Viking Press: New York; 1962; or in the film version, Forman M (Director). One flew over the cuckoo's nest. USA: United Artists; 1975. Widely available including: https://www.youtube.com/ watch? $\mathrm{v}=\mathrm{lcAU} 0-O f d V s$ or https://play.google.com/store/movies/details?id=lcAU0-OfdVs or https://itunes.apple.com/gb/movie/one-flew-over-the-cuckoos-nest/id278291787.

Open Access This chapter is licensed under the terms of the Creative Commons Attribution 4.0 International License (http://creativecommons.org/licenses/by/4.0/), which permits use, sharing, adaptation, distribution and reproduction in any medium or format, as long as you give appropriate credit to the original author(s) and the source, provide a link to the Creative Commons license and indicate if changes were made.

The images or other third party material in this chapter are included in the chapter's Creative Commons license, unless indicated otherwise in a credit line to the material. If material is not included in the chapter's Creative Commons license and your intended use is not permitted by statutory regulation or exceeds the permitted use, you will need to obtain permission directly from the copyright holder.

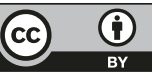

